\title{
O PASTOREIO EM PORTUGAL (SUBSÍDIOS PARA O SEU ESTUDO)
}

Alberto Martinho

\section{INTRODUÇÃO}

O pastoreio em Portugal começa a chegar formalmente até nós, sobretudo através das referências inscritas nos forais, cartas régias, alvarás régios, códigos de posturas municipais ${ }^{1}$.

Também nalguns estudos históricos se inserem descrições etnográficas que fornecem dados importantes sobre o mesmo tema.

No entanto os estudos sistemáticos sobre o tema foram conduzidos, entre outros, por Tude de Sousa ${ }^{2}$, Amorim Girão ${ }^{3}$, Jorge Dias ${ }^{4}$, Orlando Ribeiro ${ }^{5}$, Alberto Martinho ${ }^{6}$.

A nível de estudos monográficos aparecem referências várias a este tema que nós citaremos neste trabalho.

\section{OS PASTORES ${ }^{7}$}

\subsection{A "vida de pastor"}

É vulgar ouvirmos frases destas ao falarmos com pastores: "nasci debaixo delas (ovelhas e cabras)", significando que nasceu e cresceu entre os referidos animais. Esta expressão foi traduzida em canções populares, como esta, por exemplo:

"Toda a vida fui pastor

Toda a vida guardei gado

Tenho um nódoa no peito

De me encostar ao cajado".

Normalmente os pastores nasciam nas casas de rés-do-chão de granito ou xisto (por exemplo, nas Beiras, Trás-os-Montes, Minho), às vezes cobertas de telhas ou mesmo de colmo (Casais de Folgosinho - Gouveia), onde o conforto era reduzido ou mesmo inexistente. Houve até um caso na aldeia de Sabugueiro (Seia), onde a 
mulher, já com dores prolongadas de parto, partiu dos campos para a sua casa, tendo nascido a criança logo que ultrapassou a porta de entrada: "só tive tempo de o aparar, para não cair no chão", como nos confidenciou.

Geralmente não frequentavam a escola ou só se processava essa frequência em dias de chuva ou de neve.

Todavia como o trabalho "é duro e de responsabilidade, não dando azo a folgas e grandes ócios"(MARTINS, 1986: 244), por vezes alguns pastores tinham certas dificuldades em contactarem com outros grupos sociais.

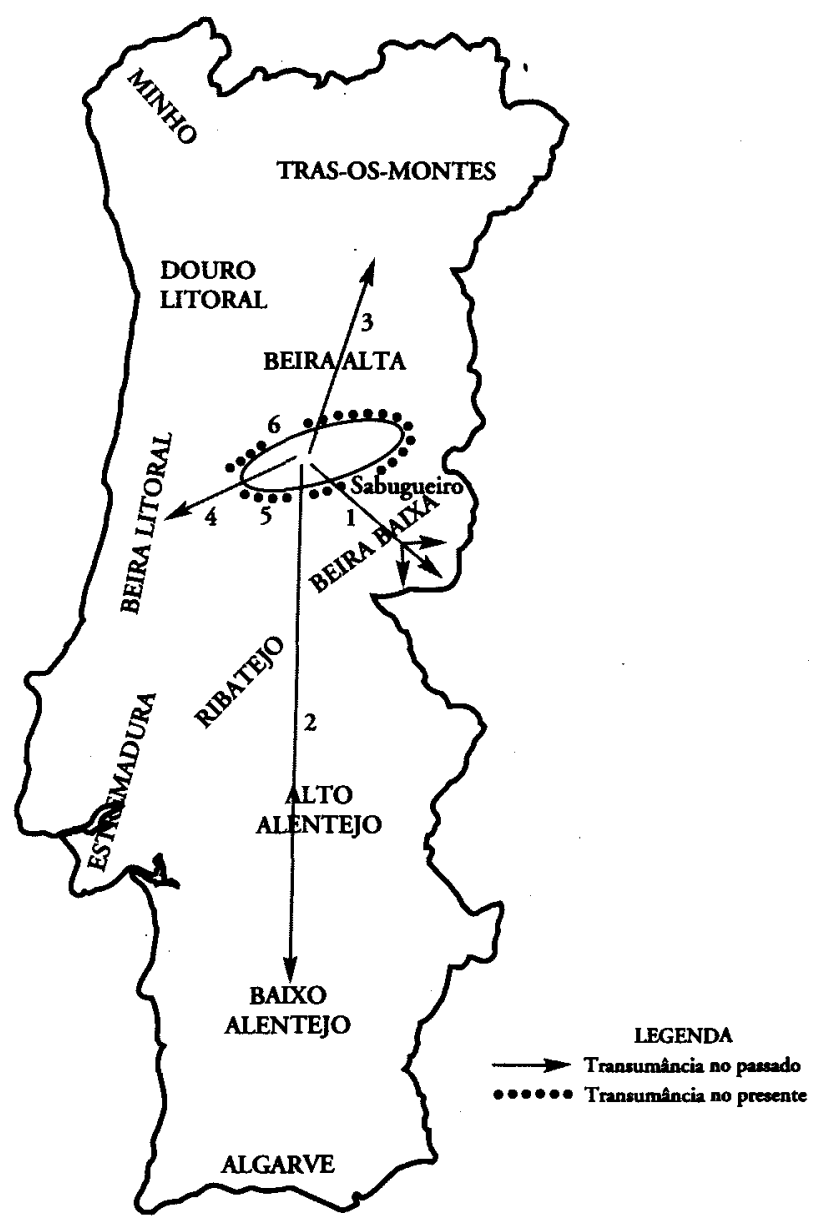


Este facto reflectia-se na feitura do serviço militar em que alguns oficiais utilizavam o vocábulo de pastor, para verberarem o comportamento dos mancebos que não se ajustassem às normas dominantes.

Tradicionalmente, o pastor caracterizava-se, como refere Jorge Dias em relação aos habitantes de Vilarinho das Furnas, por viver de modo a que ganhasse "o pão de cada dia" 8 .

Em Rio de Onor, o pastor para guardar o rebanho comunitário das ovelhas até era contratado fora da povoação. $O$ seu dia decorria assim:

"Quando o pastor chega à noite com o rebanho, dirige-se para a casa do vizinho e senta-se na cozinha, junto ao fogo, até lhe darem de cear. Depois vai dormir no lugar que lhe destinarem e, pela manhã cedo, recebe o almoço e a merenda que leva no surrão, para comer durante o dia, enquanto anda no monte"(DIAS, 1953:180).

Na ocupação de pastor "subsistem aspectos ligados à pobreza e dependência", como refere Brian Juan O'Neill ${ }^{9}$.

Muitas vezes não recebem salário em dinheiro, recebendo uma parte da lã e das crias de um rebanho(CUTILEIRO, 1977: 77).

Como já referimos, o pastor passa a maior parte da sua vida deambulando pelos campos. É que a transumância a isso obriga: o caso das deslocações no passado do gado da Serra da Estrela para a "invernada" em direcção ao rio Douro, aos campos de Coimbra, ao Alentejo ${ }^{10}$, em percursos que duravam 8-9 dias em que o pastor transportava a merenda, em conjunto com a capa, os safões e o anho que por vezes nascia no caminho, dando origem a verdadeiras cenas bíblicas.

Actualmente as deslocações processam-se para zonas mais próximas (cuja duração é de 1-2 dias) ${ }^{11}$. O pastoreio é mantido, sobretudo, nos planaltos e montanhas de Trás-os-Montes, da Beira Alta e Beira Baixa, complementarmente com a exploração agrícola ${ }^{12}$.

Os pastores, sobretudo nas zonas de montanha ${ }^{13}$, costumavam, por vezes, ocupar alguns tempos livres tocando (flauta, pífaro) e jogando. "Em Trás-os-Montes, por exemplo, jogos violentos como os da Reca e do Malhão são típicos do Alvão e do Barroso, onde predomina aliás a pecuária"(CABRAL, 1984: 175).

A Associação de Jogos Tradicionais do distrito da Guarda está neste momento a divulgar, entre outros, o jogo do pau, que foi sempre um divertimento dos pastores. Em épocas festivas - 24 de Junho, subida dos rebanhos para a Serra da Estrela, na transumância de Verão, ou nas festas dos santos padroeiros das aldeias, como por exemplo em Linhares da Beira (Celorico da Beira) e Videmonte (Guarda) - os pastores enfeitam os cornos das ovelhas, carneiros e chibos, com flores confeccionadas para o efeito, bem como o lombo dos mesmos.

Estas ocasiões são comemoradas com grande abundância de comidas e bebidas ${ }^{14}$. 
$\operatorname{MAPA}$ N. ${ }^{\circ} 2$

TRANSUMÂNCIA DE VERÃO, NO PRESENTE, DO «GADO» DA «TERRA CHÃ»

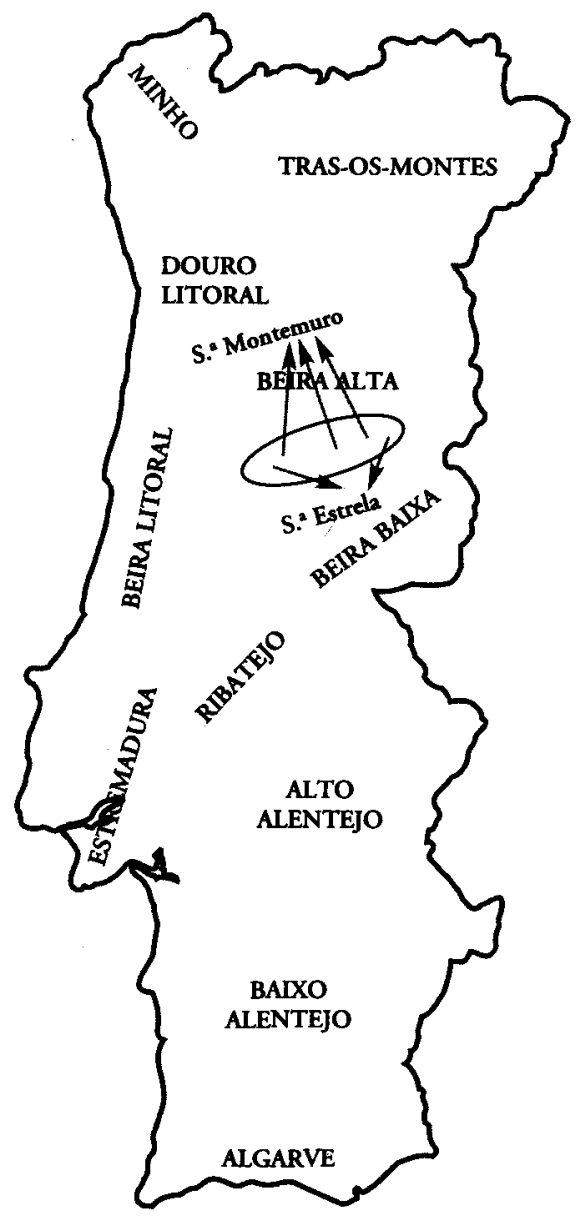

Tais festas tinham uma amplitude maior na altura dos casamentos. Aí os pais dos noivos ofereciam duas, três ou quatro "reses" cada, para serem consumidas na véspera do casamento (o que dava origem ao início da festa), durante o dia da cerimónia e no dia seguinte. Ainda hoje se matém esta tradição, principalmente nas aldeias de montanha da Serra Estrela.

Hoje, porém, está a processar-se uma mudança nas condições económicas dos pastores ${ }^{15}$. Todavia, a imagem tradicional do pastor "rude", "ignorante" para alguns, ainda não está apagada ou redefinida. Assim há raparigas que se recusam a casar com filhos de pastores (com um grau de poupança entesourada considerável) porque "cheiram a queijo", isto é, não têm os sábados e domingos livres, não 
têm motorizadas, nem automóvel e não consomem frequentemente os produtos, publicitados pela televisão e rádio (cervejas, enlatados).

\subsection{Análise de um caso - Os pastores do Sabugueiro}

Antigamente (1930) a vida de pastor "era uma vida triste, não se ganhava para se comer. Quem tinha as ovelhitas sempre enchia a barriga, porque se fazia o soro. Deitava-se um bocado de água na caldeira onde se aparava o soro, depois juntava-se uma ou duas tigelas de farinha ..."

No Inverno a hora de levantar era por volta das 7-8. "Fazia-se um panela de sopa. Por vezes deitava-se água na sopa que crescia da noite e coziam-se umas batatas que eram comidas com duas ou três azeitonas e pão. "Em seguida iam para os campos colher lenha para a lareira e matos para "a cama" das ovelhas. Como não havia burros, "os burros éramos nós", como nos revelou uma sabugueirense uma vez que o transporte era efectuado à cabeça. Ao meio-dia comia-se uma tigela de sopa e pão. Não havia "condutos" (carnes, peixes, etc.). Os que tinham gado comiam melhor, porque havia alguns que comiam o "caldo sem tempero algum".

À noite repetia-se a sopa, ou o soro que caía da francela, as batatas com azeitonas, uma vez ou outra um pouco de carne de porco frita e pão. Só nos dias de festa se matava uma galinha ou se comprava mais um pouco de carne de porco. Não se comia "a chanfana" 16 como agora. A carne de ovelha só era comida pela família quando um lobo atacava o rebanho e matava algumas "reses" ou quando "morria alguma ovelha que já não segurava as águas" ${ }^{17}$. O mesmo acontecia com o vinho, que só era bebido em dias de festa.

No que diz respeito ao vestuário, as mulheres e as filhas vestiam-se com tecidos de chita e também com pano "surrobeco". "Era o xaile que tapava as misérias", querendo significar as roupas normalmente remendadas e velhas. O homem vestia as calças e a camisola feita de pano "surrobeco". Para isso, as mulheres escaldavam a lã em caldeiras, com as fogueiras realizadas junto da ribeira, após as tosquias. Em seguida lavavam a lã em água fria. Depois dirigiam-se às fábricas de Manteigas, onde era "ordenada", isto $e$, transformada em pano "surrobeco" e também em pano preto. $O$ industrial trocava a lã por panos, no momento, ou então tecia e enviava-a por um portador para o seu destinatário. $O$ homem trazia sempre consigo os safões e a capa, porque "quem tapa o frio tapa o calor". Se havia alguns que podiam vestir, no dia do casamento, um fato de tecido "surrobeco" ou preto, outros porém pediam um fato emprestado, bem como o lenço, no caso da mulher e os anéis (alianças). Nesse dia, porém, matavam-se umas reses para que houvesse fartura. "As prendas eram poucas. Um ou outro recebia uma ou outra peça (uma arca, uma mesa, um cobertor) mas a maior parte pegava na capa às 
costas numa "corcha"18 e num cobertor. Em seguida dirigia-se com a noiva para a casita normalmente cedida pela família, para se deitarem, na primeira noite do casamento. Na maior parte dos casos não tinham lençóis e o trem de cozinha resumia-se a uma panela e barro, duas ou três tigelas (que eram permutadas por pão de centeio na Idanha-a-nova) para lá se comerem as batatas com as "cocharras"19.

No que respeita à habitação as casas eram de rés-do-chão e primeiro andar, terminando directamente nos caibros com telhas à vista. Uma pastora conta-nos que: "éramos doze irmãos. A nossa casa tinha só dois quartitos e outro mais pequeno à entrada da porta, onde dormiam os rapazes até aos doze anos. Os mais velhos iam dormir à palheira na barra, por cima das ovelhas. Lá ficavam até que se casavam. Na casa ficava um quarto para os pais e outro para as raparigas. Como da cama se viam as telhas, quando chovia, as nossas caras ficavam todas molhadas. Até a neve ficava sobre as "corchas" que cobriam as camas. O que nos valia eram os fogueirões que fazíamos na lareira." E a mesma interlocutora continua: "Hoje, tudo quer viver nas comodidades, andam feitos lordens (lordes) e senhoras. Já se julgam umas pessoas muito ricas e felizes à vista doutros tempos".

\section{OS EFECTIVOS ANIMAIS}

Nos arrolamentos gerais de "gado" de 1940 e 1955 já assistimos a um ligeiro decréscimo de efectivos pecuários nalgumas regiões. No que respeita aos ovinos, essa queda é mais visível nos arrolamentos de 1972 e 1979 (ver anexo 1), em que, com excepção dos distritos de Lisboa e Setúbal, todos os restantes perderam alguns efectivos. A quebra dos caprinos foi menos acentuada.

A queda verificada, a partir do censo de 1955 , deve-se aos preços baixos do queijo, da carne e da lã (ver anexo 2). Por outro lado, a florestação, levada a efeito pelos serviços ofíciais nalgumas regiōes (Serra do Açor, Serra da Estrela, Serra do Marão, Serra da Lapa), deu origem a que muitos tivessem que vender os rebanhos ao desbarato.

Tal prática deveu-se ao facto dos referidos serviços não respeitarem os interesses das populações e arborizarem zonas vitais para a sobrevivência dos rebanhos, muitas delas constituindo extensas zonas de baldios.

Houve até um caso, em Alvoco da Serra (Seia), em que um pastor foi multado em $70 \$ 00$ pelo facto do gado ter entrado "na floresta". Este caso deveu-se ao facto do vento ter aberto a porta do curral onde se encontravam as "cabeças de gado". Enquanto o pastor andava a procurar as ovelhas deixou cair o chapéu no terreno florestado. Por esse facto também foi multado ${ }^{20}$. Este sistema de repressão pela 
multa também foi aplicado na Serra da Peneda (Minho) aos possuidores de ovelhas e cabras, provocando grandes decréscimos nos efectivos 21 .

Esta situação, aliada a uma agricultura de subsistência, em muitos casos, deu origem a que muitos emigrassem nas décadas de 1960 e $1970^{22}$, sobretudo para os países da Europa ${ }^{23}$.

Este facto também é relatado pelo Padre António Fontes, em relação a algumas aldeias do Barroso, em Trás-os Montes, em que menciona que "houve pastores que emigraram, famílias que tiveram de mudar de terra, de hábitos, de região"(FONTES, 1977: II, 83)

\section{O PASTOREIO E O FABRICO DO QUEIJO}

\subsection{O Problema}

Se compararmos os dados fornecidos pelos arrolamentos dos gados desde 1940-1979, verificamos que se está perante um decréscimo substancial dos efectivos pecuários, como já analisámos.

Das razões enunciadas pelos pastores da área do Parque Natural da Serra da Estrela e concelhos vizinhos, em $1978^{24}$, destacam-se entre outros: o baixo preço do queijo ${ }^{25}$, as doenças dos animais, a falta de um sistema de crédito, a idade avançada dos pastores (85, isto é, 94\% tinham 40 e mais anos de idade) (gráfico n. ${ }^{\circ}$ 1).

Embora os estudos aprofundados que realizámos tivessem lugar na região da Serra da Estrela, podemos, no entanto, afirmar que noutras regiões, por observação directa, chegámos a detectar a existência de causas semelhantes.

$\mathrm{Na}$ área da Serra da Estrela foi possível constatar que, pela valorização dos preços do queijo, pela melhoria sanitária dos animais, pela criação de linhas de crédito e pela produção de queijo "Serra da Estrela" foi possível atrair gente jovem para este sector. No presente (1990), verificamos que há concelhos onde os efectivos aumentaram (Penalva do Castelo), outros onde estabilizaram (Celorico da Beira), havendo, por outro lado, também outros onde se verificou um ligeiro decréscimo (Guarda).

Uma consequência geral é palpável: a quebra abrupta que se vinha verificando nos efectivos pecuários estancou, havendo uma tendência para a estabilização na região considerada. 
QUADRO N. ${ }^{\circ} 1$

Quantidade de arrobas de queijo transacionados no mercado de Fornos de Algodres (1950 - 1979)

\begin{tabular}{|l|l|l|l|l|l|}
\hline ANO & ARROBAS & ANO & ARROBAS & ANO & ARROBAS \\
\hline 1950 & 28930 & 1960 & 29078,6 & 1970 & 28280,6 \\
1951 & 22312 & 1961 & 29862,6 & 1971 & 16727,25 \\
1952 & 26998 & 1962 & 32462,5 & 1972 & 17371 \\
1953 & 27886,8 & 1963 & 28958,6 & 1973 & 16908 \\
1954 & 32399,6 & 1964 & 30398,6 & 1974 & 14818 \\
1955 & 28562,8 & 1965 & 28001,8 & 1975 & 14692 \\
1956 & 28853,6 & 1966 & 29542,5 & 1976 & 15938 \\
1957 & 28989,3 & 1967 & 30675,6 & 1977 & 15099,4 \\
1958 & 28466,1 & 1968 & 31945,8 & 1978 & 18749 \\
1959 & 29606,3 & 1969 & 23941,6 & 1979 & 16593 \\
\hline
\end{tabular}

GRÁFICO N ${ }^{\circ} 1$

PIRÂMIDE DE IDADES DOS PASTORES E PASTORAS (1980) NA ÁREA DE PRODUÇÃO DO QUEIJO DA SERRA DA ESTRELA

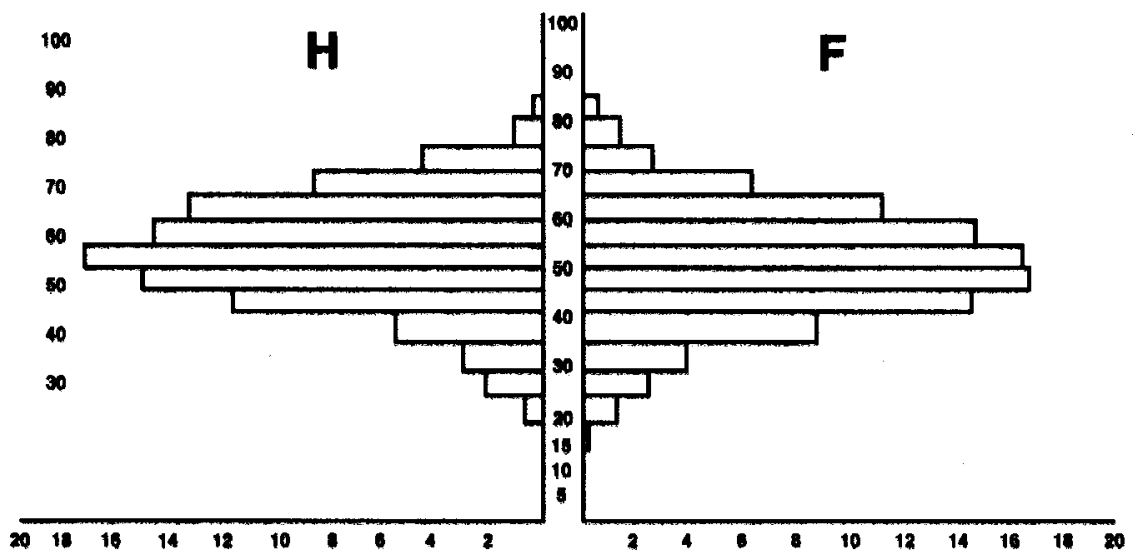




\subsection{As Feiras - Concurso de Queijo "Serra da Estrela"}

\subsubsection{As Origens}

Em Dezembro de 1977 foi designado um pequeno grupo para arrancar com a fundação do Parque Natural da Serra da Estrela (P. N. S. E.). Constituíam esse grupo, um antropólogo, duas assistentes sociais e um engenheiro técnico agrário. Deram início às suas actividades com um trabalho de campo, baseado na aplicação de um questionário sobre o pastoreio e o queijo "Serra da Estrela" aos 638 pastores existentes na área do Parque. Os resultados destes estudos foram publicados posteriormente (MARTINHO, 1978). No decorrer desta investigação, aproveitou-se a oportunidade para uma observação directa do quadro natural e humano em que se desenvolvia a produção de queijo "Serra da Estrela". Nestes contactos e em sessões realizadas à noite nas aldeias, com os pastores e demais população, foi possível arrolar as necessidades objectivas e outras, sentidas pela população.

A partir do inventário quantitativo complementado pela análise qualitativa, foi possível seleccionar algumas intervenções posteriores. Assim, deu-se início a um programa sanitário nos ovinos e caprinos, suportando o parque $50 \%$ dos custos. O Parque e o Banco Espírito santo \& Comercial de Lisboa (BESCL) criaram uma linha de crédito especial para a aquisição de ovelhas e construção de currais para a sua instalação. Esta linha de crédito foi alargada posteriormente a outros sectores, aquando da recente renegociação. $O$ Parque também concebeu a organização das feiras-concurso de queijo "Serra da Estrela". Os objectivos que presidiram a estes certames resumem-se nos seguintes pontos:

1. Divulgar o queijo "Serra da Estrela" junto do grande público;

2. Possibilitar a venda directa entre o produtor e o consumidor que, até então, era restrita;

3. Promover a qualidade através dos concursos;

4. Promover e valorizar a profissão de pastor, anteriormente marginalizada.

\subsubsection{Estreitar a colaboração entre Parque, autarquias e população, tendo em vista o desenvolvimento rural integrado}

Em 1978 deu-se início aos concursos-feiras do queijo (ver quadro n. ${ }^{\circ}$ 2). Para tal, foi elaborado um regulamento. A equipa de animação do Parque efectuou sessões à noite nas aldeias para a divulgação do concurso e do regulamento. Os concursos tiveram base concelhia. $O$ júri era constituído pelas mulheres dos pastores, que faziam diariamente o queijo, e pelos maridos que se deslocavam a concelhos diferentes dos seus, para a análise do queijo. As autarquias e o BESCL colabora- 
ram nos prémios pecuniários, além do Parque suportar um prémio de presença a cada concorrente na ordem dos $500 \$ 00$.

Estes certames traduziram um aumento de preço ao produtor (de $100 \$ 00 \mathrm{~kg}$ passou a $250 \$ 00 \mathrm{~kg}$, a preço de mercado, em 1978), além da redefinição da imagem tradicional do pastor que se deveu em parte à boa cobertura dada pelos orgãos de comunição social. A marcação destes certames, na época do Carnaval, coincidiu com a existência de grandes nevões na Serra, o que deu origem a grande afluência de visitantes. A ideia que presidiu à organização destes concursos nesta época tem a ver com o seguinte: nas feiras quinzenais (Celorico, Fornos de Algodres, entre outras) eram dois ou três grandes comerciantes de queijo de Lisboa e Porto que chegavam, conversavam entre si e, por este modo, determinavam "os preços". Ora pretendia-se, com estas novas feiras-concursos, quebrar tal vício, uma vez que "os pastores ficavam nas mãos deles".

Tornava-se, pois, necessário colocar o produto no consumidor, passando o menos possível por estes intermediários. Foi o que se procurou fazer, aproveitando os "turistas da neve" que visitam esta região no Inverno, com especial destaque no Carnaval.

\subsubsection{O periodo $1978-1990$}

A partir da dinâmica gerada por estas iniciativas, os pastores sugeriram a realização de concursos de ovinos, tendo em vista o aumento da produção de leite.

Em 1979 os concursos-feiras do queijo "Serra da Estrela" já se efectuaram em todos os concelhos do Parque, à excepção da Covilhã onde predomina sobretudo a cabra. Por outro lado, já integraram o júri destes concursos, para além das queijeiras, dois técnicos do Laboratório Nacional de Engenharia e Tecnologia Alimentar (LNETI), reformulando o regulamento do concurso na base de uma tabela de classificação.

Um dos resultados, assaz significativo, foi que não havia diferenças notórias entre a classificação elaborada pelos investigadores e a realizada pelas queijeiras, com a diferença de que a destas últimas não era passível de uma expressão numérica. Após esta classificação, os técnicos do LNETI procediam à análise química dos queijos classificados nos cinco primeiros lugares de cada concurso. Tal pesquisa permitiu que, em 1980, tivesse lugar, após a realização destes concursos, a primeira finalíssima do queijo da "Serra da Estrela" nos concelhos de Fornos de Algodres e Oliveira do Hospital, na qual, todavia, os técnicos do LNETI não participaram por entenderem não estarem reunidas as condições para garantir o trabalho idóneo.

Tais certames tiveram lugar a pedido dos pastores e das autarquias após a realização de um trabalho de prospecção levado a cabo pela referida equipa. Até 
1981 verificou-se uma melhoria nítida na qualidade dos queijos, quer no que respeita ao tamanho do queijo, como sobretudo ao doseamento do cardo e do sal. Também no que toca aos cuidados higiénicos se verificou uma nítida melhoria.

\section{QUADRO N.. ${ }^{\circ}$}

Número de concorrentes nas feiras. - Concurso de Queijo da Serra (1978/90)

\begin{tabular}{|c|c|c|c|c|c|c|c|c|c|c|r|}
\hline Ano & Seia & Gouveia & $\begin{array}{c}\text { Man- } \\
\text { teigas }\end{array}$ & $\begin{array}{c}\text { Celorico } \\
\text { da } \\
\text { Beira }\end{array}$ & Guarda & $\begin{array}{c}\text { Fornos } \\
\text { de } \\
\text { Algodres }\end{array}$ & $\begin{array}{c}\text { Oliveira } \\
\text { do } \\
\text { Hospital }\end{array}$ & $\begin{array}{c}\text { Penalva } \\
\text { do } \\
\text { Castelo }\end{array}$ & $\begin{array}{c}\text { Aguiar } \\
\text { da } \\
\text { Beira }\end{array}$ & Trancoso & TOTAL \\
\hline 1978 & 79 & 90 & 49 & & & & & & & & 218 \\
1979 & 114 & 95 & 32 & $322 \mathrm{a})$ & 54 & & & & & & 617 \\
1980 & $82 \mathrm{~b})$ & $101 \mathrm{c})$ & 33 & $359 \mathrm{~d})$ & $52 \mathrm{e})$ & 208 & 78 & & & & 913 \\
1981 & $75 \mathrm{f})$ & $68 \mathrm{~g})$ & 26 & $299 \mathrm{~h})$ & $49 \mathrm{i})$ & 234 & 72 & & & & 823 \\
1982 & 61 & 81 & 49 & 160 & 64 & 266 & 59 & & & & 740 \\
1983 & 63 & 130 & 38 & 150 & 65 & 269 & 66 & 50 & & & 831 \\
1984 & 121 & 146 & 25 & $266 \mathrm{i})$ & 60 & 228 & 64 & 58 & & & 968 \\
1985 & 125 & 118 & 18 & $271 \mathrm{j})$ & 65 & 192 & 66 & 53 & 67 & & 975 \\
1986 & 104 & 102 & 14 & 306 & 58 & 131 & 65 & 91 & 45 & & 916 \\
1987 & 119 & 103 & 18 & 300 & 62 & 211 & 74 & 102 & 59 & & 1048 \\
1988 & 75 & 119 & 12 & $293 \mathrm{j})$ & 66 & 194 & 71 & 119 & 45 & & 994 \\
1989 & 86 & 118 & 8 & $305 \mathrm{j})$ & 69 & 169 & 67 & 122 & 45 & 62 & 1051 \\
1990 & 90 & $112 \mathrm{i})$ & $11 \mathrm{i})$ & 312 & h) & 175 & $75 \mathrm{i})$ & $103 \mathrm{i})$ & 42 & 57 & 977 \\
\hline
\end{tabular}
a) Destes, 85 pertenciam a freguesias fora da área do Parque.
b) Destes, 8 pertenciam a freguesias fora da área do Parque.
c) Destes, 24 pertenciam a freguesias fora da área do Parque.
d) Destes, 133 pertenciam a freguesias fora da área do Parque.
e) Destes, 8 pertenciam a freguesias fora da área do Parque.
f) Destes, 3 pertenciam a freguesias fora da área do Parque.
g) Destes, 106 pertenciam a freguesias fora da área do Parque.
i) Destes, 10 pertenciam a freguesias fora da área do Parque.
j) Dados provisórios.
h) Já não se realizou.
i) Foram realizadas já com a denominação exposição-feira e não feira-concurso.

Também no concelho de Mangualde teve lugar este ano a 1.a exposição-feira, promovida pela Câmara Municipal e pela associação concelhia dos Pastores.

Nesta data teve lugar a suspensão das referidas acções, baseada em razões de ordem política, por parte da ex-secretária de Estado do ambiente ${ }^{26}$, ficando o Parque impedido de organizar e controlar tecnicamente tais certames. 
A partir de 1981 as Câmaras situadas na área do Parque ${ }^{27}$ foram as responsáveis pela organização dos mencionados certames. Todavia, foram substituídas pelo Parque e todas, à excepção da de Celorico da Beira, têm solicitado, ao Parque, a nomeação dos júris de apreciação do queijo. No entanto, as outras Câmaras situadas fora da área do Parque ${ }^{28}$ continuaram a solicitar auxílio aos técnicos do Parque, quer para a sua organização, quer para a indicação do júri. Não pode deixar de levantar-se o reparo quanto à idoneidade destes técnicos para classificar os queijos concorrentes, a qual, não existindo, põe desde logo em causa a seriedade do concurso em favor de aspectos meramente folcloricos. Assim, foram convidados para integrar o júri, já não as queijeiras oriundas dos outros concelhos, bem como os técnicos do LNETI, mas sim comerciantes de queijo, funcionários das autarquias. Chegou a fazer-se a classificação dos queijos sem sequer se abrirem os mesmos (para análise do sabor, textura da massa, etc.), limitando-se tal júri à análise exterior dos mesmos! O que interessava mais nestes concursos era estarem no palco vários Ministros e Secretários de Estado, "para a entrega dos prémios aos pastores premiados", ao som de bandas de música. Quase que se chegou a avaliar o grau de importância destes concursos pelo número de membros do governo e demais entidades oficiais que rodopiavam esse dia pelo certame. Em 1991, nalguns concelhos estes certames passaram a designar-se "festa-convívio do pastor" deixando-se, assim, para segundo plano o aspecto do concurso e da qualidade dos queijos.

\subsubsection{Breve Sintese}

Em 1981, os técnicos do P.N.S.E. reforçaram a crítica que de há muito vinham fazendo: as feiras-concurso constituem um meio e não um fim em si mesmas. Torna-se necessário um plano de desenvolvimento integrado do queijo "Serra da Estrela", que passa pela melhoria das pastagens, apoio sanitário aos animais, constraste leiteiro, melhoria da higiene do leite, assistência tecnológica aos produtores do queijo e melhoria das condições ambientais de cura e de todas as infra-estruturas de apoio à ovinicultura.

Só em março de 1985, parece começar a desenhar-se algum apoio institucional do Ministério da Agricultura. Dantes só era possível contar com alguns funcionários do mesmo, a nível individual.

O P.N.S.E., o IFADAP, o LNETI, o BESCL e as Autarquias estão empenhadas em ultimar um plano integrado sobre o queijo "Serra da Estrela". Oxalá que a inércia da burocracia, aliada a pequenas políticas, não bloqueie os recursos financeiros e humanos indispensáveis à consecução cabal deste objectivo. Se tal acontecer, os sinos dobrarão a finados pelo QUEIJO SERRA DA ESTRELA. 


\section{ASPECTOS VISÍVEIS E "INVISÍVEIS" DA MUDANÇA EM CURSO}

\subsection{O preço do queijo}

O queijo representa cada vez mais o principal produto da exploração ovina. Como já atrás referimos, a época mais importante, para o fabrico do queijo Serra da Estrela, compreende o período Outubro-Abril. Ora, acontece que, até 1950, a transumância efectiva-se para os "campos" do Douro, de Coimbra, de Castelo Branco e do Alentejo, precisamente nesta época, e tendo como objectivo principal a criação de borregos e borregas, especialmente estas últimas, o queijo só se começava a fabricar a partir dos meados de Março, após o regresso. Nessa transumância apenas o homem fabricava alguns queijos. A mulher ficava na aldeia de origem. Estes factores, aliados ao clima dos locais de transumância, pode explicar o não fabrico do queijo. A procura do queijo era pequena nessa época relativamente recuada.

O queijo da região serrana - St. ${ }^{2}$ Marinha, Paços da Serra, Póvoa Nova, Sabugueiro - era comprado por comerciantes das Contenças (concelho de Mangualde) e de Cativelos (concelho de Gouveia) ${ }^{29}$, que se deslocavam às aldeias para tal fim. Após o fecho da transacção, por exemplo, no Sabugueiro, as queijeiras transportavam o queijo à cabeça até $S$ St. $^{a}$ Marinha (2 duas horas a pé) e dali era transportado em deligências (carros puxados por mulas ou cavalos), até à estação de caminho-de-ferro.

$\mathrm{Na}$ região consumia-se pouco queijo. $\mathrm{O}$ queijo fresco (queijetas) e requeijão eram vendidos em Gouveia, Passo da Serra, S. Romão, Seia e Manteigas, onde havia algumas fábricas de têxteis e, por isso, o poder de compra era superior aos das aldeias onde quase todos os moradores possuíam algumas "cabeças" de gado. Era o gado quem tirava a fome das casas, no dizer de alguns. $O$ queijo era porém consumido a partir de Maio, época em que era de pior qualidade ${ }^{30} \mathrm{e}$ em que a pasta já estava dura, o que facilitava o transporte no saco como "conduto", quer no pastoreio, quer nas ceifas e nas malhas de centeio, quer ainda no subsequente amanho nas sementeiras.

Decorrente desta situação, o pastor realizava algum dinheiro, sobretudo a partir de Agosto (correspondendo ao fim da transumância de Verão), com a venda de algumas "crias", com os borregos, no período de um mês após a parição, a partir de Outubro.

A evolução do preço do queijo, verificada sobretudo nos últimos anos (a partir de 1978) (ver anexo n. ${ }^{\circ} 3$ ), não é alheia à acção levada a efeito pelo Parque Natural da Serra da Estrela no que respeita ao queijo "Serra da Estrela"31. Esta aç̧ão foi decorrente sobretudo da realização dos concursos-feiras de queijo da Serra da Estrela e de outras acções atrás referidas, em que os principais objectivos foram:

- melhoria da qualidade do queijo e, consequentemente, a melhoria da qualidade de vida das populações. 
— a redefinição da imagem do pastor também foi alcançada, como já foi referido.

Se, em 1978, na região considerada, o queijo rendeu aos pastores 200000 contos, esse valor ultrapassou os 2000000 de contos em 1989.

\subsection{Os pastores e o queijo da serra: da tradição à mudança}

Um dos aspectos que temos a salientar refere-se ao aumento substancial do rendimento produzido na exploração, sobretudo devido à valorização do queijo, mais do que da carne ou da lã. Esse dinheiro deu origem, num primeiro tempo, à melhoria da casa, à feitura de uma nova casa - que não rivaliza, nem em tamanho nem no estilo, com a dos emigrantes - ou à compra de uma quinta nova ou da que traziam, "à renda", do senhorio. Num caso ou noutro, assistimos à aquisição de casas senhoriais a antigos proprietários terratenentes ou aos seus descendentes. Em relação ao interior da casa, a mudança verificou-se na aquisição do fogão a gás e do frigorífico, sendo a arca congeladora uma excepção. A nível dos quartos e da sala, uma boa parte adquiriu mobílias novas (algumas imitando o denominado estilo séc. XVII). A nível do vestuário, se bem que nas zonas montanhosas o homem continue a usar as calças de surrobeco e a capa, contudo deixou de usar esta indumentária aos domingos. Contrariamente ao passado, neste dia, passou a vestir o fato confeccionado pelo alfaiate da ladeia ou aldeias vizinhas ou adquirido já confeccionado.

A mulher já veste, nos dias de semana, peças compradas já confeccionadas (sobretudo na feira semanal ou quinzenal e não na loja comercial da vila). Contudo ainda não vai ao cabeleireiro. Embora continue a usar o lenço (já não o tradicional) na cabeça e o xaile preto, quando faz frio, também substitui este último na ida à missa aos domingos ou na procissão do santo padroeiro da aldeia, pela saia e pelo casaco ou pela blusa, muitas vezes confeccionados pela modista da aldeia ou então adquiridos na feira. Tal como dantes, o pastor quando quer ir à vila continua a deslocar-se a pé, de burro, ou no autocarro. Raríssimos são os que compraram automóvel. Um ou outro adquiriram uma pequena camionete (que é normalmente conduzida por um filho) e que serve para transportar: a lenha para a lareira, o estrume para as terras e o queijo para a feira, o pai, a mãe e os irmãos, bem como familiares e amigos, para as festas e romarias onde vão "pagar a promessa" ao santo padroeiro.

A maior parte do dinheiro vai constituir depósitos a prazo nos bancos. Daqui, por exemplo, vem alguma animosidade por parte de camponeses parciais ${ }^{32} \mathrm{e}$ semi-proletários ${ }^{33}$, na aldeia do Sabugueiro (Serra da estrela), que os acusam de serem os ricos da terra (alguns mesmo ultrapassando a posição, na escala de riqueza, de certos comerciantes tradicionais). À tal animosidade os pastores res- 
pondem: "se as ovelhas dão assim tanto dinheiro porque é que tu não as arranjas"? No caso do interlocotor já ter sido pastor a resposta é do tipo: "se tu foste já pastor, porque as deixaste (ovelhas)? Por alguma coisa foi! $O$ dinheiro cobiçazeo (sic) tu, o trabalho não. Não vês que o pastor não tem domingos nem dias santos. Chova ou neve elas (ovelhas) têm que comer". Por vezes estas conversas sobem de tom (travam-se geralmente nas tabernas) e, como há uns circunstantes que apoiam um e outros que apoiam o outro, acontece que, por vezes, da violência verbal chega-se ao confronto físico. Por vezes o taberneiro é que separa os contendores, dizendo: "Agora só se discutem as riquezas de cada um. Ninguém conta anedotas nem contos como antigamente, agora só há ódios e invejas. Só se ouve dizer: eu não preciso nada de ti, eu tenho muito dinheiro no banco!"

No que respeita aos filhos "poucos querem ser pastores, pois a vida de pastor é uma vida de escravidão", dizem alguns. Alguns pastores queixam-se amarguradamente, dizendo que não têm "herdeiros" (no sentido de não haver quem lhe siga os passos na criação das ovelhas).

No concelho de Gouveia (Serra da Estrela) o veterinário municipal tem levado a efeito cursos para a formação de ovinicultores (no sentido empresarial), uma vez que ele próprio se recusa a utilizar a palavra pastor ${ }^{34}$. Consiste em organizar sessões à noite ou logo após o almoço (período em que as ovelhas estão "ao rodeio"), na Primavera e no Verão, em que vários oradores expõem de modo prático ensinamentos sobre pastagens, sanidade animal, contabilidade, noções de marketing, etc.

Alguns filhos de pastores transformaram-se em comerciantes de queijo, de ovelhas e de artigos de vestuário em pele, bem como de produtos artesanais de todo o tipo, como aconteceu na aldeia do Sabugueiro, em S. Romão e Pinhanços no Concelho de Seia. Um caso de rejuvenecimento dos pastores situa-se no concelho de Gouveia. Neste concelho está a verificar-se um aumento dos efectivos ovinos, ao mesmo tempo que se verifica um aumento no número médio de "cabeças" por exploração, como aliás se está a verificar em algumas zonas de Trás-os-Montes e Alentejo. Também aqui se reflectem já, nalguns exemplos, o resultado da aplicação das medidas do F.E.O.G.A. ${ }^{35}$.

Se, por um lado, estamos a assinalar estas novas tendências, por outro, verificamos que uma parte importante do pastoreio tradicional na Beira Alta, Beira Litoral e Minho processa-se em complemento com a agricultura de subsistência. Por outro lado, reformados ${ }^{36}$, ex-emigrantes e até semi-proletários possuem explorações que, em média, não ultrapassam os 30 animais, inseridos em esquemas de pluriactividade e de plurirrendimento. 


\section{3. $\mathrm{O}$ associativismo formal}

Como já referimos, sobretudo nas regiões de montanha, o associativismo era patente, desde há longos anos. $\mathrm{O}$ trabalho desenvolvido, a nível do Parque Natural da Serra da Estrela, deu origem a uma forte tomada de consciência, por parte de alguns líderes locais, da importância que o associativismo teve no passado e que poderia continuar a ter no futuro.

A primeira associação concelhia de pastores surgiu no concelho de Celorico da Beira (1986), tendo-se constituído outras em seguida, nos concelhos de Seia, Gouveia, Fornos de Algodres, Penalva do Castelo, Guarda, Manteigas, Oliveira do Hospital e Mangualde. A Federação dos Produtores de Queijo "Serra da Estrela" (Faproserra) foi constituída em 1987, com sede provisória em Gouveia.

Podemos dizer que, no presente momento, são os pastores que têm na mão os seus próprios destinos, através da via associativa. A Federação candidatou-se a constituir a entidade certificadora do queijo "Serra da Estrela", a partir do laboratório de controle de qualidade instalado em Celorico da Beira. Esta associação, em colaboração com a Associação dos Criadores de Ovinos Serra da Estrela (ANCOSE) $^{37}$, envidam esforços para, em comum, estabelecerem com as entidades oficiais nacionais e estrangeiras os programas e projectos desde as pastagens, passando pela sanidade animal, formação profissional dos pastores e queijeiras, controle de qualidade e certificação do queijo e demais acções integradoras. Está em projecto a constituição de uma associação para a comercialização de carne de borrego e do queijo "Serra da Estrela."

Em Beja foi constituída, em 1983, a associação de Criadores de Ovinos do Sul, que representa actualmente 650 associados, com um efectivo de 220000 ovinos e 30000 caprinos.

Neste momento já existem no país 11 associações de criadores de ovelhas e cabras. $O$ trabalho desenvolvido, na área da Serra da estrela, no que concerne à promoção dos queijos, propagou-se a outras regiões do país.

Assim, tiveram lugar, em 1983, a primeira feira-concurso do queijo de Tomar; em 1985, a primeira feira-concurso do queijo do Rabaçal (Coimbra); em 1986, a primeira feira-concurso do queijo de Serpa (Alentejo); em 1989, a primeira feira-concurso do queijo de Azeitão (Setúbal). Estas iniciativas desenvolveram-se em moldes semelhantes às da área da Serra da Estrela e muitas delas com o apoio expresso dos técnicos do Parque.

\section{6. À GUISA DE CONCLUSÃO}

1. Verifica-se que a valorização do queijo está a contribuir para o redimensionamento dos rebanhos nalgumas regiões (Alentejo, Beiras) e para a revalorização da exploração ovina. 
2. Constata-se que a exploração ovina de pequena dimensão (até 20-30 animais) tende a desaparecer, enquanto unidade económica empresarial. Poderá, contudo, vir a subsistir como complemento da agricultura a tempo parcial, realizado sobretudo por iniciativa de ex-emigrantes e reformados.

3. O associativismo formalizado tem contribuído e poderá contribuir ainda mais para que os actores sociais - os pastores - passem a ter na mão os seus próprios destinos.

4. Os pastores-proprietários, apesar do aumento substancial do rendimento auferido, sobretudo após 1978, não têm tendência para a ostentação, como se verifica noutros grupos sociais. 


\section{ANEXO 1}

Efectivos de ovinos e caprinos em Portugal (1972): Manifestantes

\begin{tabular}{|l|c|c|c|c|c|c|}
\cline { 2 - 7 } \multicolumn{1}{c|}{} & \multicolumn{7}{c|}{} & \multicolumn{2}{c|}{} \\
\hline DISTRIT & $\begin{array}{c}\text { Número } \\
\text { de } \\
\text { Manifestantes }\end{array}$ & $\begin{array}{c}\text { Número } \\
\text { de } \\
\text { cabeças }\end{array}$ & $\begin{array}{c}\text { Média } \\
\text { Cabéfas } \\
\text { manifestadas }\end{array}$ & $\begin{array}{c}\text { Número } \\
\text { de } \\
\text { Manifestantes }\end{array}$ & $\begin{array}{c}\text { Número } \\
\text { de } \\
\text { cabeças }\end{array}$ & $\begin{array}{c}\text { Média } \\
\text { Cabeças } \\
\text { manifestadas }\end{array}$ \\
\hline Aveiro & 11971 & 36034 & 3 & 4957 & 11180 & 2,3 \\
Beja & 5405 & 373560 & 69,1 & 4673 & 69697 & 14,9 \\
Braga & 9276 & 33881 & 3,6 & 4646 & 22535 & 4,8 \\
Bragança & 1993 & 173356 & 87 & 2254 & 52882 & 23,5 \\
C. Branco & 5533 & 253177 & 45,8 & 21154 & 117369 & 5,6 \\
Coimbra & 20796 & 78496 & 3,8 & 21881 & 48765 & 2,2 \\
Évora & 3657 & 343218 & 93,9 & 2618 & 41999 & 16 \\
Faro & 5110 & 46008 & 9 & 3660 & 21886 & 6 \\
Guarda & 4624 & 156802 & 33,9 & 11229 & 45130 & 4 \\
Leiria & 16397 & 50402 & 3 & 13000 & 32844 & 2,5 \\
Lisboa & 3504 & 64808 & 18,5 & 1691 & 11182 & 6,6 \\
Portalegre & 2632 & 280232 & 106,5 & 4376 & 64949 & 14,8 \\
Porto & 14573 & 43004 & 3 & 3236 & 8360 & 2,6 \\
Santarém & 19503 & 139653 & 7,2 & 19563 & 66805 & 3,4 \\
Setúbal & 2223 & 120628 & 54,3 & 1869 & 16061 & 8,6 \\
V. Castelo & 15845 & 55043 & 3,5 & 3746 & 24001 & 6,4 \\
V. Real & 5822 & 61416 & 10,6 & 4110 & 35225 & 8,6 \\
Viseu & 23658 & 110476 & 4,7 & 19652 & 50153 & 2,6 \\
TOTAL & 172522 & 2420194 & 14 & 148315 & 741023 & 5 \\
\hline & & & & & & 5 \\
\hline
\end{tabular}

FONTE: I.N.E. 


\section{ANEXO 2}

Efectivos de ovinos e caprinos em Portugal (1979): Explorações

\begin{tabular}{|l|c|c|c|r|c|c|}
\cline { 2 - 7 } \multicolumn{1}{c|}{} & \multicolumn{3}{c|}{ OVINOS } & \multicolumn{3}{c|}{ CAPRINOS } \\
\hline DISTRIT & $\begin{array}{c}\text { Número } \\
\text { de } \\
\text { Explorações }\end{array}$ & $\begin{array}{c}\text { Número } \\
\text { de } \\
\text { cabeças }\end{array}$ & $\begin{array}{c}\text { Média } \\
\text { Cabeças } \\
\text { Explorações }\end{array}$ & $\begin{array}{c}\text { Número } \\
\text { de } \\
\text { Explorą̧̃̃es }\end{array}$ & $\begin{array}{c}\text { Número } \\
\text { de } \\
\text { cabeças }\end{array}$ & $\begin{array}{c}\text { Média } \\
\text { Cabeças } \\
\text { Explorações }\end{array}$ \\
\hline Aveiro & 7677 & 27857 & 3,6 & 7119 & 19920 & 2,8 \\
Beja & 3906 & 350589 & 89,8 & 3378 & 77054 & 22,8 \\
Braga & 4921 & 22783 & 4,6 & 3447 & 22397 & 6,5 \\
Bragança & 1856 & 156415 & 84,3 & 1821 & 42764 & 23,4 \\
C. Branco & 3377 & 161963 & 48,1 & 17084 & 84497 & 4,9 \\
Coimbra & 13890 & 52700 & 3,8 & 19608 & 45064 & 2,3 \\
Évora & 2954 & 330903 & 112 & 1686 & 35825 & 21,2 \\
Faro & 3072 & 33301 & 10,8 & 3787 & 22437 & 5,9 \\
Guarda & 3128 & 114206 & 36,5 & 9232 & 40184 & 4,4 \\
Leiria & 13075 & 47923 & 2,7 & 12011 & 39081 & 3,3 \\
Lisboa & 3633 & 65039 & 17,9 & 1704 & 13620 & 8 \\
Portalegre & 2290 & 226672 & 99 & 3556 & 47140 & 13,3 \\
Porto & 8630 & 30485 & 3,5 & 2484 & 8484 & 3,4 \\
Santarém & 16961 & 125762 & 7,4 & 19132 & 69131 & 3,6 \\
Setúbal & 1641 & 131488 & 80,1 & 1594 & 22387 & 14 \\
V. Castelo & 13548 & 52940 & 3,9 & 3069 & 23249 & 7,6 \\
V. Real & 4113 & 46070 & 11,2 & 4067 & 49323 & 12,1 \\
Viseu & 15920 & 80811 & 5 & 16880 & 53318 & 3,2 \\
TOTAL & 124582 & 2057907 & 16,5 & 131659 & 715875 & 5,4 \\
\hline
\end{tabular}

FONTE: I.N.E. 


\section{ANEXO 3}

Preços médios do gado e derivados (1960/1990)

na Aldeia do Sabugueiro (Seia)

(Em escudos)

\begin{tabular}{|r|r|r|r|r|r|r|r|r|r|r|r|}
\hline \multirow{2}{*}{ Anos } & \multicolumn{2}{|c|}{ Borrego } & \multicolumn{2}{|c|}{ Carneiro } & \multicolumn{2}{c|}{ Ovelha } & \multicolumn{2}{|c|}{ Cabra } & $\begin{array}{c}\text { Leite } \\
\text { Ovelha }\end{array}$ & Queijo & Lã \\
\cline { 2 - 10 } & $\begin{array}{r}\text { Animal } \\
\text { vivo }\end{array}$ & $\begin{array}{r}\text { Quilo } \\
\text { morto }\end{array}$ & $\begin{array}{c}\text { Animal } \\
\text { vivo }\end{array}$ & $\begin{array}{c}\text { Quilo } \\
\text { morto }\end{array}$ & $\begin{array}{c}\text { Animal } \\
\text { vivo }\end{array}$ & $\begin{array}{r}\text { Quilo } \\
\text { morto }\end{array}$ & $\begin{array}{c}\text { Animal } \\
\text { vivo }\end{array}$ & Quilo & Litro & Quilo & Quilo \\
\hline 1960 & 75 & 20 & 400 & - & 300 & 15 & 300 & - & 2,5 & 18 & 17 \\
1972 & 160 & 50 & 700 & - & 600 & 45 & 600 & - & 10 & 70 & 23 \\
1978 & 600 & 150 & 3000 & - & 2500 & 120 & 2500 & - & 20 & 2300 & 60 \\
1980 & 800 & 220 & 7000 & - & 5000 & 180 & 4000 & - & 30 & 350 & 100 \\
1981 & 1000 & 250 & 8000 & - & 5500 & 200 & 4500 & - & 35 & 500 & 110 \\
1982 & 1200 & 300 & 9000 & - & 6500 & 230 & 5000 & - & 40 & 600 & 120 \\
1983 & 1500 & 350 & 10000 & - & 8000 & 250 & 6000 & - & 50 & 700 & 140 \\
1984 & 2000 & 450 & 12000 & - & 10000 & 280 & 8000 & - & 60 & 800 & 160 \\
1985 & 2500 & 550 & 14000 & - & 12000 & 320 & 10000 & - & 80 & 1000 & 200 \\
1986 & 3500 & 700 & 18000 & - & 15000 & 380 & 12000 & - & 100 & 1250 & 200 \\
1987 & 5000 & 750 & 25000 & - & 20000 & 450 & 15000 & - & 120 & 1500 & 210 \\
1988 & 6000 & 850 & 30000 & - & 25000 & 500 & 20000 & - & 150 & 1800 & 220 \\
1989 & 8000 & 950 & 40000 & - & 30000 & 550 & 25000 & - & 200 & 2000 & 250 \\
1990 & 10000 & 1000 & 50000 & - & 35000 & 600 & 30000 & - & 250 & 2200 & 230 \\
\hline
\end{tabular}




\section{ANEXO 4}

Preço médio por arroba de queijo na *Terra Chã» *

\begin{tabular}{|c|c|}
\hline ANOS & PREÇOS \\
\hline 1974 & $1000 \$ 00-1400 \$ 00$ \\
1975 & $1300 \$ 00-1700 \$ 00$ \\
1977 & $1800 \$ 00-2250 \$ 00$ \\
1978 & $2250 \$ 00-3750 \$ 00$ \\
1979 & $4000 \$ 00-5000 \$ 00$ \\
1980 & $5100 \$ 00-7500 \$ 00$ \\
1981 & $7600 \$ 00-9000 \$ 00$ \\
1982 & $9100 \$ 00-12000 \$ 00$ \\
1983 & $12500 \$ 00-14500 \$ 00$ \\
1984 & $15000 \$ 00-17500 \$ 00$ \\
1985 & $18000 \$ 00-20000 \$ 00$ \\
1986 & $20000 \$ 00-25000 \$ 00$ \\
1987 & $25000 \$ 00-30000 \$ 00$ \\
1988 & $25000 \$ 00-35000 \$ 00$ \\
1989 & $25000 \$ 00-35000 \$ 00$ \\
1990 & $30000 \$ 00-40000 \$ 00$ \\
\hline
\end{tabular}

* Planalto da Beira Alta

\section{NOTAS}

1. Abilio Mendes do Amaral "Os pastores da Serra da Estrela", Revista Beira Alta, vol XXIX, n. ${ }^{\circ} 3,1970$, p. 355-399.

2. Tude de Sousa, Serra do Gerez, Estudos, aspectos, paisagens, Porto, 1909, Gerez; Notas etnográficas, arqueológicas e históricas, Coimbra, 1927

3. Aristides de Amorim Girão, Montemuro. A mais desconhecida Serra de Portugal, Coimbra, 1940; Lições de geografia humana, Coimbra, 1936.

4. Jorge Dias "Les troupeaux transhumants et leurs chemins", Comptes rendus du Congrés International de Geógraphie, Lisbonne, 1949, T. III, Lisboa, 195; Das Hirtenwesen in Portugal, Budapest, Akadémiai Kiadó, 1969.

5. Orlando Ribeiro, "Contribuição para o estudo do pastoreio na Serra da Estrela", Revista da Faculdade de Letras de Lisboa, tomo VII, 1940-1941.

6. Alberto Martinho, O pastoreio e o queijo da serra, Parque Natural da Serra da Estrela, Lisboa, 1978; O queijo da serra, Comissão de Coordenação da Região Centro, Coimbra, 1980. 
7. Esta expressão englobará os que são donos dos efectivos pecuários e que se ocupam deles permanentemente, como também aqueles que se ocupam permanentemente dos efectivos, embora sem serem proprietários dos mesmos.

8. Jorge Dias, Vilarinho da furna, Lisboa, Imprensa Nacional, 1981, (reedição), p. 114

9. Brian Juan O'Neill, Proprietários, Lavradores e Jornaleiras, Lisboa, publicações Dom Quixote, 1984, p. 105.

10. Alberto Martinho, Sabugueiro, uma aldeia da Serra da estrela, Lisboa, I.S.C.S.P., 1972 (Edição policopiada), p. 109-131.

Numa destas caminhadas até Évora, um pastor, ainda novo, acompanhava o pai e o tio que conduziam um grande rebanho do Sabugueiro (Seia). Na subida do rio Tejo para Nisa ouviu-se o barulho de uns cavalos que transportavam uns "senhores com umas bandeiras e gritavam: Viva a República (Outubro 1910)". Os Sabugueirenses tiraram os chapéus da cabeça encostando as ovelhas para os cavalos passarem melhor no caminho, sem que se tivessem apercebido da mudança ocorrida no País (fim da monarquia).

11. Ver mapas 1 e 2.

12. Orlando Ribeiro, "Contribuição para o estudo do pastoreio na Serra da estrela", Revista da Faculdade de Letras de Lisboa, tomo VII, 1940-1941, p. 220-232.

13. Nestas, por vezes, os rebanhos da aldeia ainda são guardados por um ou dois pastores, de forma colectiva tomando o nome de "correr a andana" (Sabugueiro-Seia), "vigia" (Gralheira Montemuro), "res" Pitões das Júnias (Gerês).

14. Na noite de 24 para 25 de Junho de 1948, uns "chotos" (donos das ovelhas transumantes) do concelho de Oliveira do Hospital pararam os rebanhos que conduziam à Lagoa Comprida, no Sabugueiro, onde o maioral os esperava. Após a refeição tomada junto das ovelhas, cantavam e dançavam. Um deslocou-se à taberna da aldeia para comprar 2 litros de vinho a que seriam misturados (no garrafăo de 5 litros) duas laranjadas. A taberneira ainda pouco experiente misturou o vinho com duas cervejas pensando que eram laranjadas. Daí a momentos chegaram os pastores protestando e dizendo: "a senhora queria envenenar-nos!" revelando que quer a taberneira quer os pastores desconheciam o que era a cerveja.

15. Ver anexos 3 e 4 e também o ponto 5.2 .

16. Carne de ovelha ou de cabra, acima de $12 \mathrm{kgs}$.

17. Estava doente.

18. Colcha de fitas, tecida em geral na Póvoa Nova - Seia, com os restos do vestuário velho que era transformado à noite em fitas, pela família, indo depois ser tecida no tear.

19. Colheres e garfos feitos de madeira, pelo pastor, enquanto guardava o gado.

20. Alberto Martinho, O pastoreio e o queijo da serra, Lisboa, Parque Natural da Serra da Estrela, 1978, p. 33.

Mariano Feio (Le bas Alentejo et l'Algarve, Évora, Centro de Ecologia aplicada da Universidade de Évora, 1983, p. 100) dá-nos conta de multas aplicadas, na década de 1940, aos pastores pelos proprietários que arborizavam a Serra de Monchique.

21. Isabel marques Medeiros, "Significado geográfico dos baldios na economia pastoril da Serra da Peneda", in Estudos em Homenagem a Mariano Feio, Lisboa, I.N.I.C. e outros, 1986, p. $340-346$. 
22. Alberto Martinho, Les enfants d'immigrés portuguais "cá e lá", Porto, Secretaria de Estado das Comunidades Portuguesas, 1986, p. 77-115; Luís Polonah, Comunidades camponesas no Parque Nacional da Peneda-Gerês, Lisboa, Serviço Nacional de Parques, Reservas e Conservação da Natureza, 1987, p. 32-38.

23. Domingos Nabais, Baraçal, Lisboa, I.S.C.S.O., 1970, Ed. policopiada.

24. Alberto Martinho, $O$ queijo da serra, Coimbra, Comissão de Coordenação da Região Centro, 1980.

25. Ver anexo 3.

26. Dr.". Margarida Borges de Carvalho. Também proibiu, a nível do Parque, todas as actividades que envolvessesm a participação das populações.

27. Seia, Gouveia, Manteigas, Guarda e Celorico da Beira.

28. Fornos de Algodres, Oliveira do Hospital, Penalva do Castelo e Aguiar da Beira.

29. Contenças tem uma estação de caminho-de-ferro e Cativelos dista dela cerca de 5 ou $6 \mathrm{kms}$.

30. Diz-se que depois de Maio o queijo é "maiado", isto é resultante da alimentação das ovelhas pelas maias das giestas.

31. Também houve a colaboração directa das Câmaras Municipais de Seia, Gouveia, Manteigas, Guarda e Celorico da Beira, dentro da área do Parque; das Câmaras de Fornos de Algodres e Oliveira do Hospital, fora da área do Parque.

32. Que trabalham nas obras públicas sazonais.

33. Fazem a migração pendular diária para as fábricas têxteis de Seia e Vodra.

34. Salienta-se que a maior parte dos frequentadores destes cursos são filhos de pastores.

35. O fundo Europeu de Orientação e Garantia Agrícola começou a ser aplicado, em Portugal, em 1986.

36. Há reformados que trabalham em actividades agrícolas, florestais e até na construção civil e obras públicas, fugindo ao controle oficial.

37. Constituída em 1981 e sediada em Oliveira do Hospital, possui 1364 sócios com um efectivo de cerca de 80000 ovinos.

\section{BIBLIOGRAFIA}

AMARAL, Abílio Mendes do, 1970, "Os pastores da Serra da Estrela", Revista Beira Alta, vol. XXIX, n. ${ }^{\circ} 3$, p. 355-399.

BALABANIAN, Oliver, 1980, Les exploirations et les problemes de l'agriculture en estremadure espagnole et dans le haut-alentejo, Braga, Typografhie Barbosa \& Xavier, L. ${ }^{\text {da }}$, 2 volumes.

CABRAL, António, 1984, "A prespectiva cultural dos jogos populares", in Estudos Transmontanos, Vila Real, $\mathrm{n} .^{\circ} 2$. 
CUTLEIRO, José, 1977, Ricos e Pobres no Alentejo, Lisboa, Livraria Sá da Costa editora.

DIAS, Jorge, 1969, Das Hirtenwesen in Portugal, Budapest, Akadémiai Kiad6.

DIAS, Jorge, 1949-51, "Les Troupeaux Transhumants e leurs chemins", Comptes rendus du Congrés Internatgional de Geográphie, T. III, Lisboa.

DIAS, Jorge, 1953, Rio de Onor, Porto, Centro de Estudos de Etnologia Peninsular.

DIAS, Jorge, 1981, Vilarinho da Furna, Lisboa, Imprensa Nacional, reedição.

FEIO, Mariano, 1983, Les bas Alentejo et l'Algarve, Évora, Centro de Ecologia Aplicada da Universidade de Évora.

FONTES, António Lourenço, 1977, Etnografia Transmontana, Montalegre, Ed. do Autor, II volume.

GIRÃO, Aristides de Amorim, 1940, Montemuro, a mais desconhecida Serra de Portugal, Coimbra, 1940.

GIRÃO, Aristides de Amorim, 1936, Lições de geografia humana, Coimbra.

GUERREIRO, Manuel Viegas, 1981, Pitões das Júnias, Lisboa, Serviço Nacional de Parques, Reservas e Património Paisagístico.

MEDEIROS, Isabel Marques, 1986, "Significado geográfico dos baldios na economia pastoril da Serra da Peneda", in Estudos em homenagem a Mariano Feio, Lisboa I.N.I.C. e outros, p. 340-346.

MARTINHO, Alberto, 1972, Sabugueiro, uma aldeia da Serra da Estrela, I.S.C.S.P., Lisboa.

MARTINHO, Alberto, 1978, O pastoreio e o queijo da serra, Parque Natural da Serra da Estrela, Lisboa.

MARTINHO, Alberto, 1981, O queijo da serra, Coimbra, Comissão de Coordenação da Região Centro.

MARTINHO, Alberto, 1986, Les enfants d'immigrés portugais "cá e lá", Secretaria de Estado das Comunidades Portuguesas, Porto.

MARTINS, Manuel Alfredo de Morais, 1986, Malpica do Tejo, Lisboa, I.S.C.S.P..

NABAIS, Domingos, 1971, Baraçal, I.S.C.S.P., Lisboa, Ed. Policopiada.

O'NEILL, Brian Juan, 1984, Proprietários, Lavradores e Jornaleiras, Lisboa, Publicações D. Quixote.

POLONAH, Luís, 1987, Comunidades camponesas no Parque Nacional da Peneda-Gerês, Lisboa, Serviço Nacional de Parques, Reservas e Conservação da Natureza.

RIBEIRO, Orlando, 1940-1941, "Contribuição para o estudo do pastoreio na Serra da Estrela", Revista da faculdade de Letras de Lisboa, tomo VII.

SOUSA, Tude de, 1909, Serra do Gerez, Estudos, aspectos, paisagens, Porto.

SOUSA, Tude de, 1927, Gerez, Notas etnográficas, arqueológicas e históricas, Coimbra, 1927. 